\title{
Aesthetic Study of Urban Square Design Against the Background of New Era
}

\author{
The Beauty of Eclecticism
}

\author{
Jialu Song \\ Sichuan Agricultural University \\ Sichuan, China
}

\begin{abstract}
Since the 18th National Congress of the Communist Party of China, socialism with Chinese characteristics has entered a new era. This is an era of multicultural symbiosis, accompanied by the transformation of people's thinking, the concept of consumption, and the transformation of aesthetic values. As the main occasion for modern people's outdoor activities, the city square should reflect the contemporary aesthetic value of the new era. The city square in the new era will discard the fixed label. This paper will explore its aesthetic possibilities from the perspective of "the beauty of eclecticism".
\end{abstract}

\section{Keywords—eclecticism; urban square; aesthetic}

\section{INTRODUCTION}

Guy Debord mentioned in his famous book The Society of Spectacle that in a society where modern production conditions are ubiquitous, life itself is manifested as a huge accumulation of landscapes. Everything that exists directly is transformed into an appearance, which explains that the urban landscape reflects the basic values of society and is the information carrier that reflects the social concept. The city square is an important node in the urban landscape, and its aesthetic value deserves our in-depth study. It not only directly reflects the structural form and type characteristics of a city, but also shows the historical patterns of the people living in it and the cultural characteristics of the city.[1]

History tells us that culture is developing in the direction of multi-integration: Greek culture represented by Socrates, Plato, and Adam Smith; Chinese culture represented by Confucius and Laozi; and Arab and Islamic culture still affecting today's society widely; under the background of cultural diversification, the construction of the artistic value of the city square in new era will inevitably become the inclusive and gathering place of multiculturalism, and it is the carrier that can most intuitively reflect the cultural symbiosis to the public. Whether it is the development of China or European culture, the reason why it can maintain its strong vitality today is because it constantly absorbs the factors of different cultures, which makes it richer, more developed and updated.

\section{THEORETICAL BASIS}

The "eclecticism" in design art comes from post-modern design. It is a post-modern creative method, which combines and compromises classical and modern, historical and fashionable, new and old design elements; this kind of compromise is based on the modernist design structure.

The beauty of eclecticism, a vertical and horizontal compromise. It includes the eclectic treatment of traditional design elements and modern design concepts of the same nation and the alienation mix between different national cultures. On the basis of focusing on the inheritance of tradition, it advocates the use of traditional symbols to recombine with the modernist symbols through the change process, so that the traditional classicism, steadiness and modern fashion and novelty are integrated; to find a breakthrough point from the traditional form and bring traditional fragments and elements into modern design. For the inheritance of tradition, it spans the gap between tradition and modernity, creates a form of beauty with a thickness and a harmonious beauty with tension, showing the depth of the fusion of traditional and modern culture. Design also restricts or changes people's lives. It embodies the preferences and habits of different peoples. [2] The "exotic mix" for the fusion of different national cultures is another kind of beauty of eclecticism. That is, the elements and languages that have completely different backgrounds and environments are combined. This kind of "exotic mix" is the result of frequent exchanges and interactions with foreign cultures during the period of economic development; in this process, the mutual complementarity, foreign exchange, and heterogeneous symbiosis have obtained this beauty of eclecticism.

The city square has a strong function, which also makes the design often ignore the attention to emotion on the basis of paying attention to function. Through the questionnaire survey, the author analyzes that: in the context of the new era, more and more people pay more attention to the aesthetic orientation and emotional experience when staying, taking part in activities, and resting in the city square while paying attention to functions; this no longer means just making one square will be ok, but a city square should focus on "what can be felt." Because people's living standards are improved, higher "superstructures" are needed. Therefore, the design of 
the city square in the new era has the soil that fosters the "beauty of the eclecticism". Studying the beauty of eclecticism in the design of urban squares is determined by the self-discipline, inclusiveness and diversity of artistic development. Relative to modernist design, the "eclecticism" is inherited and innovative for the creation of various elements and contexts. It is not only the inheritance of traditional culture, but also the re-understanding of modern culture; it is both respect for tradition and review and reflection in the modern environment. It advocates the preservation, inheritance of traditional culture and the acceptance of advanced foreign culture. On this basis, compromises are made to create new forms of art. Compared with the single and rational functionalism of modernism, this highlights innovation, and more reflects the law of artistic development of absorption and re-creation, which is in line with the theoretical needs of the design of urban squares in the new era.

\section{APPLICATION VALUE}

Under the background of the new era, people's aesthetic interest in urban squares is a pursuit of spiritual level in today's material foundation, which has great practical significance. The design of the city square not only reflects the fashion trend of the new era, but also has the residual temperature of historical humanities; it not only conforms to the aesthetics of the color and texture of the new era, but also the nostalgia for the traditional texture. The longevity of a design does not refer to the permanent form of a material, but the longevity of a culture. Under the violent impact of multiculturalism, urban squares are over-formalistic, exaggerated or single. Therefore, the study of the artistic construction of urban square design from the perspective of eclectic aesthetics breaks through the situation that only emphasizes the function of urban square design but neglects the exploration of its cultural and emotional diversity; it is necessary to re-examine the thinking and explore new ideas.

Then, it is important to achieve theoretical inheritance and innovative research. Inheritance is the premise of innovation, and innovation is the best inheritance. The theory of "eclectic beauty" stems from postmodernism, but it is rarely mentioned in today's design flow. This is a design method that can't be avoided. The eclecticism is not a concession, but a balance in multiple integration and interaction. Based on the inheritance of this theory, the study of this topic seeks to explore the aesthetic construction of the compromise method in the design of urban squares, so as to carry out extensible, developmental and innovative research.

\section{Status QuO AT Home AND AbRoAd}

The Italian Plaza in New Orleans, USA designed by Charles Moore. The designer forms a superposition of colors through the form of façade composition, which is energetic and flamboyant, in line with the Italian national culture and traditional aesthetics. In the material of the façade composition, the designer not only changed the color of the original Roman architecture, but also wrapped the stigma with bright stainless steel. The same architectural form carried the combination of traditional stone and modern metal materials. The imprint of the era in traditional architecture is both traditional and avant-garde. On the square floor composition, the designer expresses the figurative elements in an abstract way, presenting the ancient Italian culture in a modern way in the entire square, which is another understanding of the traditional Italian culture. Through this transformation of understanding, the designer grasps the whole design from the perspective of humanistic spirit. It is full of symbolic meaning and has a fun romance. It satisfies the homesickness of the Italian residents in a foreign country and shows strong ploy and humanity.

Through the eclecticism and a combination of façade and plane composition, as well as the ingenious combination of color and material, the designer combines traditional and modern perfectly, making the urban square design both traditional and modern, satisfying functional requirements and in line with people's emotional needs about human feelings.

\section{Key Points of Urban SQUare DESIGN UNDER THE BACKGROUND OF NEW ERA}

The city square in the new era emphasizes humanism. Today, with the pluralistic development of society, how to integrate multiculturalism into a heterogeneous and compatible symbiosis needs to start from the composition of the city square itself.

\section{A. Well-shaped Practice--- The Construction Form of Square}

1) Linear composition: the space is divided by straight lines to distinguish different functional partitions. The use of different lengths and different lines can bring different rhythm and space to the square. The inheritance of art refers to the inheritance and reservation of the dignity of the art of the previous generation, which left the essence of the art of the previous generation. For example, in the traditional Chinese style, the frame view is mostly composed of neat lines and patterns. This traditional form can be divided into a sense of sequence and space by modern materials such as metal and steel frames. This compromise of traditional and modern elements makes the space both modern and fashionable with rich humanistic feelings.

2) Curve composition: the square formed by the curve form is more flexible, but it is also difficult to shape. When dealing with terrain with high altitude difference, the design should pay attention to the fluidity and rhythm of the curve. The way the curve is constructed is the representative of surrealism. The design of the square in the new era needs to subvert the traditional streamlined flow with the international standard. It is necessary to respect the geographical characteristics and actual needs of the square. What's more, it's important to integrate the high-end composition of the spirit of the times into the design. The eclectic use of curve is indispensable square design style in new era. 


\section{B. Well-paved Practice--- Streamline Distribution of Road} Traffic in Square

Traffic flow to the square is like blood vessels to the human body. It plays a very important role in the design of the square. The square design under the new era has paid more attention to emotion on the basis of accurately constructing functions. Reasonable traffic flow line design can solve some problems in the field, and can also guide people through the path, so that people can experience different emotional guidance in different square space forms. The interlacing of paths can also make different spatial cultures intergrowth. This heterogeneous pluralistic fusion is also a compromise, which is an unavoidable problem in the square design in new era.

\section{Well-established Practices--- The Basic Elements of the Square Design in the New Era}

The outdoor environment is the most closely connected place between human and nature, people and people, people and society. The elements of outdoor environment are very complex, including natural environment, human environment and social environment.[3]

1) Greening: it's necessary to respect the ecological and aesthetic basis, respect the functional needs and people's needs, consider the local climate and soil factors, consider the seasonal changes and design a variety of plants, finally forming a landscape with distinct seasons and rich communities. .

2) Paving: paving is an important element in the design of the square. For the square, the paving area is generally relatively large. The square can be partitioned by pavements of different materials, colors and patterns to enrich the spatial level of the square.

3) Waterscape: people have the instinct to appreciate water, use water, and get close to water. Adding hydrophilic space in the square can relax people, and at the same time reduce dust and increase humidity in the air. However, safety should be considered in design to create a safe and hydrophilic space.

4) Lighting: In the main activity space, its necessary to ensure the brightness of light. In the place of sculpture, green, water space, different lighting effects can be formed by reflection and diffuse reflection. At the same time, according to the seasons, different colors of light should be designed. For example, in summer, cool light should be used to create a cool feeling. In winter, warm lighting can be used to make the square warm.

The design of public environmental facilities is moving from a single category to a pluralistic style and further to be more specialized. [4] In the square design elements, the key to the beauty of compromise is to bring traditional elements and fragments into modern design through modern techniques, showing the depth of integration between the old and new. For example, in the waterscape design, the stacked waters and stones in the Chinese classical gardens can be layered and simplified, and the landscapes are arranged in a vertical plane by means of schist-rock and mountain water.
This is completely expressed in modern design. The traditional atmosphere makes the waterscape design in the square more contemporary and more in line with the aesthetic needs of the new era. In this process, the fusion of tradition and modernity has achieved a compromise.

5) Well-affected practices --- the construction of the theme elements and the humanistic environment: The plaza is a comprehensive venue that provides cultural, entertainmental, leisurely, recreational, municipal activities and exchange of ideas and opinions. The eclectic aesthetic demand is to extract characteristic elements from different geographical features, different seasons, and different national cultural activities in the design, and apply them to the design to create squares of different themes and human environments in new era. The design of urban squares needs the reconstruction of change. These foreign mixes show the transcendence and variability with the change of people's aesthetic consciousness. The design of urban squares is no longer just the design of function and space, but it is more about giving people the emotional attachment of "positive energy". From a macro perspective, urban environmental design should focus on green design, sustainable development, and people-oriented macro direction. Starting from the elements of the city square, it is environmentally conscious and displays the humanities.

\section{The Aesthetic Value of Eclectic Beauty in the DESIGN OF URBAN SQUARES IN THE NEW ERA}

For designers, it is innovation to deeply understand the spirit of the place before design and to coordinate and coordinate various factors for creation. [5] The "eclectic" creative approach means a mix of languages. Take a "heterogeneous mixture" of elements that do not use nature, different ages, and different sources, and consider each other and take care of each other. The aesthetic value of the "compromise method" in the design of urban squares is mainly through its application in the form of composition, decoration and application, metaphorical use of spiritual connotation and attention to emotions. In the future development, the use of new technologies and new materials makes the "eclectic beauty" and urban square design perfectly combined. The "compromise" for the fusion of contradictory elements is not only in the form, but in the future, it also highlights the use of high-tech products combining materials, texture and texture. This development trend is also an important aesthetic value.

\section{THE DifFICULTIES OF ECLECTIC BEAUTY IN THE DESIGN OF URBAN SQUARES IN THE NEW ERA}

How do urban squares in the new era have historical and humanistic feelings? The hustle and bustle of historical culture and the historical and cultural elements are not the characteristics of the city square. Walter Gropes said: "for whoever thinks that he has invented "eternal beauty," he will be trapped in imitation and stagnation." The design of the city square under the "eclectic beauty" bears the transcendence of this design concept. Through diversified 
and multi-perspectives, it can get rid of the ambiguous meaning and non-logical expression, and actively create the subversive beauty with new contradictory forms to produce a design trend that belongs to the city square.

\section{A. Geting Rid of the Fetters}

In the design of urban squares, this is a detachment from the over emphasis on modernist design concepts and the neglect of the aesthetic sense of form. The rationalization of modernism makes the repressed thoughts begin to pursue breakthroughs. The design of the city square is freed from bondage, placed in a free design atmosphere, pursuing the grasp of existence, and escaping the constraints of time, which has produced humanized design requirements in line with humanity. The ambiguous and eclectic regional form design is ubiquitous in people's sensory feelings. It uses the object of "square" to influence people's material life world and establish a multi-dimensional intrinsic connection with people's spiritual world. The design pursues complex, ambiguous, and vague results, and is no longer bound by a single, unified mind. It is also no longer an independent form of indifferent isolated existence, but a kind of human beauty that reflects human feelings in square design.

\section{B. Ambiguities}

"Contradictions" and "diversities" are important features that constitute this ambiguity. The "ambiguity" in the design of urban squares seems to be simple, but it is a design language that contains all kinds of uncertainties and endless recollections. It incorporates specific elements of history and the language of the times, mixes some contradictory, opposite elements in a complex way, with a variety of ambiguities, and produces a plausible ambiguity: perhaps absurd, funny, arrogant, violent and all kinds of weird symbols, all kinds of ambiguous visual effects. A sense of shocking feelings will be achieved through these complex blends. This may be manifested in the form of ambiguity in the design of the city square: the dislocation and the repulsive effect between the components; or the functional ambiguity: the inner and outer regions penetrate each other, and the edges of the boundary design are blurred. This ambiguity means not making the design weird, but seeking to change in a fixed design mindset. Therefore, the artistic charm of ambiguity is to subvert the inertia thinking, break the traditional aesthetic, and make the super-functional language acceptable in the design.

\section{The Beauty of Subversion}

Wang Mingju wrote in "Fuzzy Aesthetics": "the absolutely pure beauty of stillness does not exist. It always embodies and contains ugliness in beauty and changes in flow." [6] The beauty of subversion is a re-examination and definition of the art culture that has taken place and is about to happen. This kind of subversion frees the designer and the public from the unconventional rational thinking mode, and enters into a passionate design atmosphere of bold innovation and subversion. This extension means a kind of new coping strategy in today's rapid development of society and culture. The subversive beauty in the design of urban squares is the subversion of the material level, replacing the clear sense of flat and straightforward expression with a sense of differential independence, thus entering the realm of freedom; it is also a subversion of contemporary art styles, a rational modern style and rigid structuralism with emphasis on the playfulness of design means and the unchanging form of structure; thus, the subversion beauty of "eclecticism" can be obtained in the design language.

These characteristics of "eclectic beauty" in the design of urban squares are the rebellion of modernist design and the expectation of future design. In the aesthetic sense, it bears the transcendence of the concept of environmental design art.

\section{CONCLUSION}

The post-modern "eclectic" approach is undoubtedly bold and avant-garde. It breaks free from the shackles of modernism and integrates its design philosophy into the design of urban squares in the context of the new era, making it both traditional and modern, both classical and avant-garde. Various different elements are symbiotic in this multiintegration, and the transformation and reconstruction of the elements make the squares unconventional and creative. The emphasis of "eclectic beauty" on humanism and emotional world makes people feel psychologically intimate. On the road of urban square design development, the new era of social multicultural development will undoubtedly make the aesthetic value of "eclectic beauty" get along with the era and become an important theoretical guide for design.

\section{REFERENCES}

[1] Elizabeth Mel. Landscape Architecture Frontiers: The Eternal Beauty of Appearance[J]. Urban Environment Design, 2008 (1) : 10-11

[2] Feng Xinqun,Yao Jing. Landscape Elements - Environmental Facilities and Landscape Sketches[M]. Jiangxi Fine Arts Publishing House,2008.1: 153

[3] Xue Wenkai. Public Environment Facility Design[M]. Liaoning Fine Arts Publishing House,2006.1: 044

[4] Xue Wenkai. Public Environment Facility Design[M]. Liaoning Fine Arts Publishing House, 2006.1: 012

[5] Yin Ying, Li Guang.The Design of Environmental Sketch[M]. Beijing Institute of Technology Press,2009.6: 013

[6] Wang Mingju. Fuzzy Aesthetics. Chinese Literary Federation Publishing Company, 2009. 